\title{
Numerical Simulation of Flow Through Settling Basin: A case study of Budhi-Ganga Hydropower Project (BHP)
}

\author{
Saurav Dulal \\ Student, M.Sc. in Hydropower Engineering, \\ Department of Civil Engineering, \\ IOE, TU, Lalitpur, Nepal
}

\author{
Dr. Santosh Bhattarai \\ Assistant Professor, M.Sc. in Hydropower Engineering, \\ Department of Civil Engineering, \\ IOE, TU, Lalitpur, Nepal
}

\author{
Prof. Dr. Bhola N S Ghimire \\ Program Coordinator, M.Sc. in Hydropower Engineering, \\ Department of Civil Engineering, \\ IOE, TU, Lalitpur, Nepal
}

\begin{abstract}
An attempt has been made in this study to check the adequacy of the trap efficiency on the deposition amount, movement, and pattern of the sediment using three-dimensional Computational Fluid Dynamics (CFD) on a settling basin of Budhi-Ganga Hydropower Project (BHP). The prediction of the amount of sediment deposition, its movement, and deposition pattern is necessary during the planning, designing, and implementation phase of the hydropower projects as sediment particles larger than a certain size can cause erosion and damages to underwater machines. Four different cases with seven different particle sizes $(0.8125 \mathrm{~mm}, 0.4375 \mathrm{~mm}, 0.2325 \mathrm{~mm}, 0.1975 \mathrm{~mm}$, $0.15375 \mathrm{~mm}, 0.10125 \mathrm{~mm}$ and $0.075 \mathrm{~mm}$ ) has been taken during simulation. Trap efficiency for different particle sizes has been compared and trap efficiency of $99 \%$ was achieved for the particle size $0.2 \mathrm{~mm}$ from numerical simulation which is a $13 \%$ deviation with the result obtained from physical modeling.
\end{abstract}

Keywords-Settling basin, deposition pattern, trap efficiency, CFD, FLOW-3D

\section{INTRODUCTION}

The continual tectonic elevating of the major mountain ranges and consequential down cutting of the river system has caused a high natural erosion rate in the Himalayan region [1]. The withdrawal of water from sediment carrying river for the development of hydropower is a big challenge. The water withdrawn directly from such a river reduces the capacity of the conveyance system and cause erosions and damages to the underwater machines such as turbine, valves, governors, etc. This causes the operation and maintenance problem that ultimately affects the economics of the generation [2]. Thus, settling basins are designed to remove suspended sediment particles greater than a particular size that settles down and deposits sediments on the bottom and they are flushed from the settling basin by certain approaches.

The study of efficient operation of settling basin, its performance, and periodic removal of the deposited sediments by water is a challenging job. To deal with sediment related problems, the prediction of the amount of sediment deposition, its movement, and deposition pattern is necessary. These predictions during the early stage and after the implementation of the project provides the best direction for the planning, designing, or improvement of the project that ultimately optimizes the cost of the project.

The settling basin is designed to decrease the mean velocity of the flow by increasing the cross-sectional area (broadening its width and depressing the floor) that reduces the turbulence level in the water flow and permit the sediment particles to settle. The settling basin is designed in such a way that it settles the smallest diameter of grain sediments in the vertical plane at the bottom of the pool before it reaches the end of the basin. The trap efficiency of a settling basin is defined as, [3]

$$
\eta=\frac{C_{\text {in }}-C_{\text {out }}}{C_{\text {in }}}
$$

Where, $\eta$ is the trap efficiency of the settling basin

$\mathrm{C}_{\text {in }}$ is the concentration of sediment at inflow

$\mathrm{C}_{\text {out }}$ is the concentration of sediment at outflow

The design codes for a settling basin are mostly based on empirical approaches that may not provide accurate results as there is strong impact on the water velocity distribution and the degree of turbulence in the settling basins, that is due to different geometry and inflow conditions $[3,4]$. Thus, to provide accurate result, certain site-specific modification is required.

The effect of the geometry is difficult to execute in 1D parameters in the analytical approaches. Owing to the complicated nature of flow dynamics of water, the functioning of headworks and settling basin is examined by Physical modeling and Numerical modeling. Physical modeling is developing a scaled physical model based on a similarity theory whereas Numerical modeling is the process of appropriately developing a mathematical model/replica for a complex physical reality that enhances engineering judgment with the power of the digital computer [5]. The physical model test is costly as well as time-consuming and on other hand Numerical modeling has certain advantages over physical modeling such as scale effect, cost, time, and interpretation. Full dynamic similitude cannot be achieved by avoiding scale effects in hydraulic models and the turbulence level in the scale model are significantly lower which culminates in the overestimation of the viscosity and the surface tension effects when simulating free surface flows over hydraulic structures using the Froude similarity [6]. Further 
numerical modeling can overcome various problems related to hydrodynamics and can process small details that may be difficult or be omitted in a physical model [7, 8].

Hanne Novik, Abha Dudhraj, et. al. [3] used STAR CCM+ for modeling of settling basin of Lower Manang Marsyangdi Hydropower Project (144MW) and the result is compared with a physical model that has been built at the Hydro Lab Pvt. Ltd. Dhemi Harlan, Dantje K. Natakusumah, Et. al. [8] has a done settling basin modeling using FLOW-3D of Karai-7 Mini hydro power plant located in Pasir Melayu Village, Sialu Kahean Sub District, Simalungun District, North Sumatera, Indonesia. Bishwo Vijaya Shrestha [9] used SIIM 1.0 on the settling basin of Mai Khola Hydropower Project, Nepal.

Thus, attempts have been made in this study to assess the flow in the settling basin by CFD to estimate the trap efficiency of the basin. The result obtained from the proposed modeling was tested with the physical modeling result of the settling basin of Budhi-Ganga Hydropower Project (BHP)-20MW, Achham, Nepal. The performance of a settling basin is mainly governed by the geometry of the basin [10]. Further, the modified cases (i. removing divider wall in each Hooper (case I), and ii. changing transition angle to $8^{\circ}$ (case II) and $12^{\circ}$ (case III)) of the proposed settling basin with different size and shapes were analyzed with deposition pattern and sediment trapping efficiency.

\section{MATERIALS AND METHODS}

\section{A. Technical Data of the Project}

The technical data of BHP-20MW are gained based on the project report. BHP is located in Achham district of Nepal between $29^{\circ} 15^{\prime} 30^{\prime \prime}$ and $29^{\circ} 18^{\prime} 35^{\prime \prime}$ latitude north and between $81^{\circ} 14^{\prime} 00^{\prime \prime}$ and $81^{\circ} 17^{\prime} 50^{\prime \prime}$ longitude east on the Budhi-Ganga river, a major tributary to the Seti river. The site location map of BHP is shown in Figure 1. The analysis in this study is fixated on the settling basin of BHP. The physical modeling of the settling basin has been carried out and these data are used in our computation and analysis.

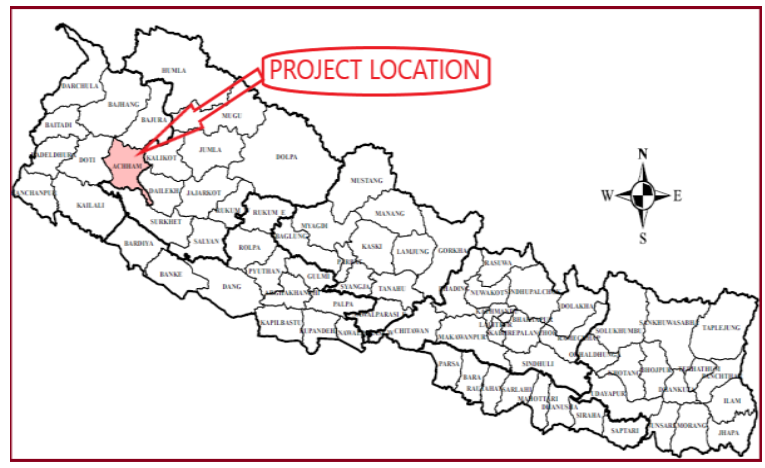

Figure 1: Site location of the Project area

\section{1) Physical Feature}

The intake is designed to withdrawal design discharge of 26 $\mathrm{m}^{3} / \mathrm{s}$ at the normal operating level of el. $720 \mathrm{~m}\left(22.1 \mathrm{~m}^{3} / \mathrm{s}\right.$ for power generation and $3.90 \mathrm{~m}^{3} / \mathrm{s}$ for flushing). The discharge from the intake is conveyed to two settling basins through two D-shaped feeder tunnels of $2.5 \mathrm{~m} \mathrm{X} 3.0 \mathrm{~m}$ size [11]. The feeder tunnels operate under pressure flow conditions. The settling basin of a $92 \mathrm{~m}$ long desilting chamber is proposed to remove suspended particles of $0.20 \mathrm{~mm}$. A basin has two chambers, each having a flushing channel with bottom width $1 \mathrm{~m}$ and a transverse slope of 1:1 on both sides. The plan of the conveyance system and the cross-sectional view of the settling basin are shown in Figure 2 and Figure 3 respectively.

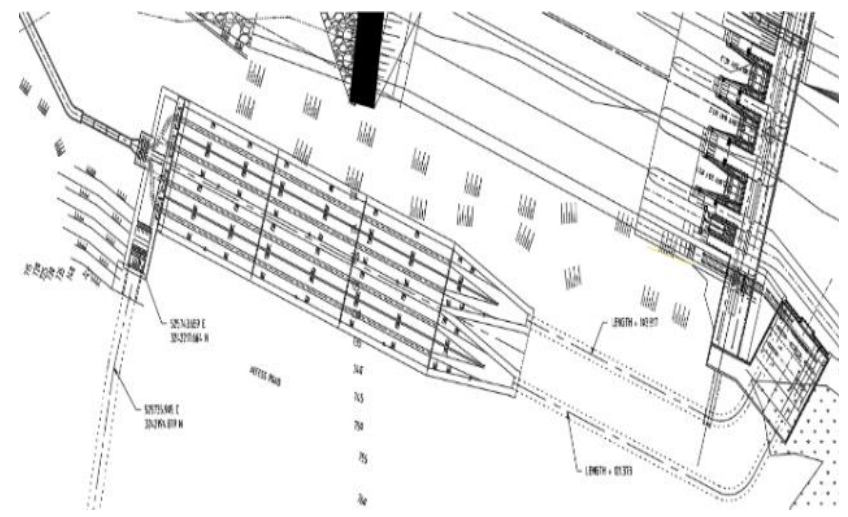

Figure 2: Plan of the Conveyance system

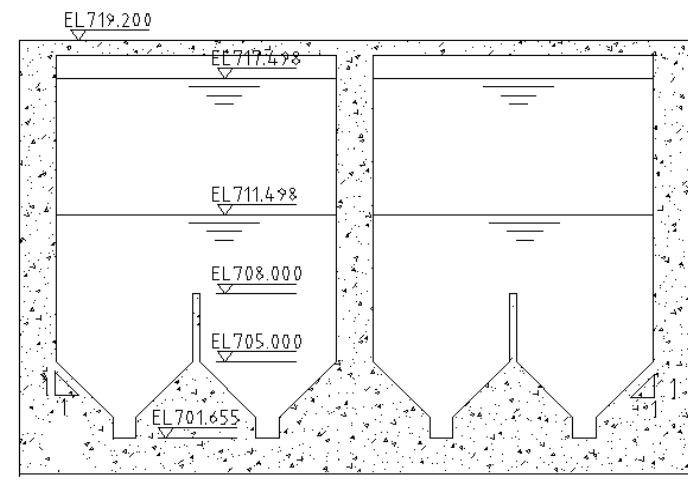

Figure 3: Cross-sectional view of the settling basin

\section{2) Inflow and Outflow Discharges}

The model was run for a single settling basin with $712.0 \mathrm{~m}$ el. at intake and a discharge of $13 \mathrm{~m}^{3} / \mathrm{s}$ was feed. The outflow discharge of $11.05 \mathrm{~m}^{3} / \mathrm{s}$ and $1.95 \mathrm{~m}^{3} / \mathrm{s}$ is maintained in HRT and flushing respectively [11].

\section{3) Sediment Data}

The model was run for 2000 ppm out of which $2.40 \%$, $4.50 \%, 38.10 \%$ and $55.00 \%$ of sediment $1.00-0.25 \mathrm{~mm}, 0.25-$ $0.180 \mathrm{~mm}, 0.180-0.075 \mathrm{~mm}$ and below $0.075 \mathrm{~mm}$ respectively [11]. Seven different particles were used to represent the range of sediments.

\section{B. Mathematical Formulation}

The equations of motion for fluids are solved with the Volume of Fluid (VOF) method numerical techniques. The Cartesian coordinates $(\mathrm{x}, \mathrm{y}, \mathrm{z})$ system is used to solve the differential equations that are formulated with area and volume porosity functions. This formulation, called FAVOR for Fractional Area/Volume Obstacle Representation Method is used to model complex geometric regions.

1) Governing Equation

The main equations used in this simulation are the mass continuity equation, the Navier-Stokes equation (momentum 
equation) and the sediment scour equations [8, 12]. The general mass continuity equation for incompressible fluids is:

Where,

$$
\frac{\partial}{\partial x}\left(u A_{x}\right)+\frac{\partial}{\partial y}\left(v A_{y}\right)+\frac{\partial}{\partial z}\left(w A_{z}\right)=\frac{R_{S O R}}{\rho}
$$

- $\mathrm{R}_{\mathrm{SOR}}$ is a mass source

- $\quad \rho$ is the fluid density

- $\quad(\mathrm{u}, \mathrm{v}, \mathrm{w})$ are velocity components in the coordinate directions $(\mathrm{x}, \mathrm{y}, \mathrm{z})$

- $\mathrm{A}_{\mathrm{x}}, \mathrm{A}_{\mathrm{y}}, \mathrm{A}_{\mathrm{z}}$ is the fractional area open to flow in the $\mathrm{x}$, $\mathrm{y}$ and $\mathrm{z}$ directions respectively

The equations of motion for the fluid velocity components $(\mathrm{u}, \mathrm{v}, \mathrm{w})$ in the three coordinate directions are the Navier-Stokes equations with some additional terms

$$
\begin{gathered}
\frac{\partial u}{\partial t}+\frac{1}{V_{F}}\left\{u A_{x} \frac{\partial u}{\partial x}+v A_{y} \frac{\partial u}{\partial y}+w A_{z} \frac{\partial u}{\partial z}\right\} \\
=-\frac{1}{\rho} \frac{\partial p}{\partial x}+G_{x}+f_{x}-b_{x}-\frac{R_{S O R}}{\rho V_{F}}(u \\
\left.-u_{w}-\delta u_{s}\right) \\
\frac{\partial v}{\partial t}+\frac{1}{V_{F}}\left\{u A_{x} \frac{\partial v}{\partial x}+v A_{y} \frac{\partial v}{\partial y}+w A_{z} \frac{\partial v}{\partial z}\right\} \\
=-\frac{1}{\rho} \frac{\partial p}{\partial y}+G_{y}+f_{y}-b_{y}-\frac{R_{S O R}}{\rho V_{F}}(v \\
\left.-v_{w}-\delta v_{s}\right) \\
\frac{\partial w}{\partial t}+\frac{1}{V_{F}}\left\{u A_{x} \frac{\partial w}{\partial x}+v A_{y} \frac{\partial w}{\partial y}+w A_{z} \frac{\partial w}{\partial z}\right\} \\
=-\frac{1}{\rho} \frac{\partial p}{\partial z}+G_{z}+f_{z}-b_{z}-\frac{R_{S O R}}{\rho V_{F}}(w \\
\left.-w_{w}-\delta w_{s}\right)
\end{gathered}
$$

Where,

- $\mathrm{V}_{\mathrm{F}}$ is the fractional volume open to flow

- $\left(\mathrm{G}_{\mathrm{x}}, \mathrm{G}_{\mathrm{y}}, \mathrm{G}_{\mathrm{z}}\right)$ are body accelerations

- $\left(\mathrm{f}_{\mathrm{x}}, \mathrm{f}_{\mathrm{y}}, \mathrm{f}_{\mathrm{z}}\right)$ are viscous accelerations

- $\quad\left(b_{x}, b_{y}, b_{z}\right)$ are flow losses in porous media or across porous baffle plates

- $\mathrm{U}_{\mathrm{w}}=\left(\mathrm{u}_{\mathrm{w}}, \mathrm{v}_{\mathrm{w}}, \mathrm{w}_{\mathrm{w}}\right)$ is the velocity of the source component, which will generally be non-zero for a mass source

- $\mathrm{U}_{\mathrm{s}}=\left(\mathrm{u}_{\mathrm{s}}, \mathrm{v}_{\mathrm{s}}, \mathrm{w}_{\mathrm{s}}\right)$ is the velocity of the fluid at the surface of the source relative to the source itself.

For each species, the suspended sediment concentration is calculated by solving its own transport equation,

Here

$$
\frac{\partial C_{s, i}}{\partial t}+\nabla \cdot\left(u_{s, i} C_{s, i}\right)=\nabla \cdot \nabla\left(D C_{s, i}\right)
$$

- $\mathrm{C}_{\mathrm{s}, \mathrm{i}}$ is the suspended sediment mass concentration of species $\mathrm{i}$, which is defined as the sediment mass per volume of fluid-sediment mixture;

- $\quad \mathrm{D}$ is the diffusivity;

- $\mathrm{u}_{\mathrm{s}, \mathrm{i}}$ is the suspended sediment velocity.

\section{Numerical Model}

\section{1) Model Geometry}

The geometry is constructed as per drawings for the base case (proposed case) settling basin of BHP by assembling solid geometric objects as shown in Figure 4. Similarly, the geometry is constructed for the modified cases by removing the dividing wall in each Hooper (case I), and changing transition angle from $10^{\circ}$ to $8^{\circ}$ (case II) and $12^{\circ}$ (case III). In the cases, the transition length for base case and case I is $27 \mathrm{~m}$ whereas for cases II and III are $34 \mathrm{~m}$ and $23 \mathrm{~m}$ respectively and other dimensions are the same for all cases.

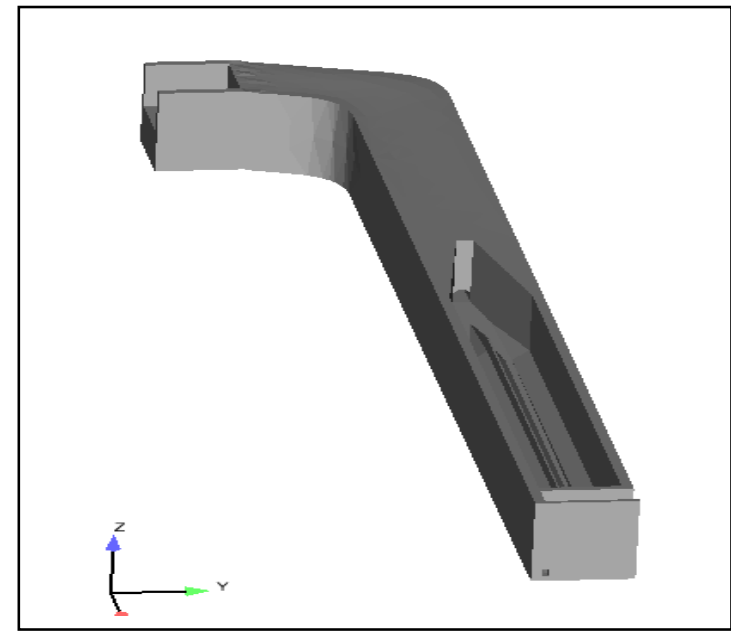

Figure 4: 3D- view of the settling basin in BHP

\section{2) Model Mesh Block}

The multiple mesh blocks are created to efficiently mesh the model flow domains. According to geometry 6 mesh blocks are defined. The mesh size adopted for the present study are as follows:

\begin{tabular}{|l|l|l|l|}
\hline S.N. & Mesh Block & Size (m) & \multicolumn{1}{c|}{ Remarks } \\
\hline 1 & Mesh Block 1 & 0.30 & Main Desander Portion \\
\hline 2 & Mesh Block 2 & 0.50 & Entry Portion \\
\hline 3 & Mesh Block 3 & 0.35 & Exit Portion \\
\hline 4 & Mesh Block 4 & 0.25 & Transition Portion \\
\hline 5 & Mesh Block 5 & 0.35 & Tunnel curve Portion \\
\hline 6 & Mesh Block 6 & 0.35 & Tunnel straight Portion \\
\hline
\end{tabular}

3) Boundary Condition

The boundary condition associated with geometry for each mesh block are as follows:

\begin{tabular}{|l|l|l|l|l|l|l|l|}
\hline S.N. & Mesh Block & $\begin{array}{c}\text { X- } \\
\text { min }\end{array}$ & $\begin{array}{c}\text { X- } \\
\text { max }\end{array}$ & $\begin{array}{c}\text { Y- } \\
\text { min }\end{array}$ & $\begin{array}{c}\text { Y- } \\
\text { max }\end{array}$ & $\begin{array}{c}\text { Z- } \\
\text { min }\end{array}$ & $\begin{array}{c}\text { Z- } \\
\text { max }\end{array}$ \\
\hline 1 & Mesh Block 1 & S & S & W & W & W & Po \\
\hline 2 & Mesh Block 2 & W & W & Vfr & S & W & Po \\
\hline 3 & Mesh Block 3 & S & Vfr & W & P & W & Po \\
\hline 4 & Mesh Block 4 & S & S & W & W & W & Po \\
\hline 5 & Mesh Block 5 & S & S & S & S & W & W \\
\hline 6 & Mesh Block 6 & S & S & W & W & W & W \\
\hline
\end{tabular}

Where, S: Symmetry

W: Wall Boundary Condition

Vfr: Volume Flow Rate

P: Specified Pressure (Stagnation pressure condition with Hydrostatic pressure)

Po: Specified Pressure with fluid fraction zero 


\section{4) Initial Condition and Physics Definition}

The opening conditions in the simulation are defined in Initial conditions. In the model, it is supposed that the settling basin is initially filled with water. Areas of fluid are defined using Fluid regions. Water at $20{ }^{\circ} \mathrm{C}$ from the fluid database is used. The acceleration due to gravity is set to $9.81 \mathrm{~m} / \mathrm{s}^{2}$ in downward Z- direction. The Renormalization Group (RNG) model was selected for the viscosity and turbulence model as it defines accurately to low-intensity turbulence flows and flows having strong shear regions. Van Rijn equation is set for the bedload transport rate equation.

\section{Physical Model}

The physical hydraulic model test of BHP was conducted in Irrigation \& Power Research Institute (IPRI) Amritsar, Punjab, India. The desander model was constructed to a geometrical scale of 1:12 which includes feeder tunnel, desander, and sediment flushing channel. The model was run with sediment load at intake as 2000 ppm for 1 hour (3.46 hours in prototype). The sediment sample deposited in a different section of the settling basin was collected and the efficiency of the basin was obtained. [11]

\section{RESULTS AND DISCUSSION}

The velocity vector is used to view the correctness of geometry and velocity distribution at different chainage are viewed along with the turbulent dissipation rate. The trapping efficiency for different sizes of sediment particles and sediment concentration distribution over the settling basin with respect to time is computed. The result shows that sediment concentration level is greater at entry and sediment concentration level goes decreasing on downstream similarly sediment concentration level is greater at the bottom level and goes decreasing on the upper level, this is due to the sediment settling phenomena and decrease in velocity of flow.

The horizontal velocities at the end of the transition, two sections in desander, and at the end of desander are viewed. Figure 5, Figure 6, Figure 7, and Figure 8 respectively represents for the base case, modified case I, modified case II, and modified case III respectively. The velocity in each case is seen decreasing while moving downstream. For the settlement of $0.20 \mathrm{~mm}$ particle, a horizontal velocity of $0.2 \mathrm{~m} / \mathrm{s}$ is required and the horizontal velocity obtained in numerical modeling at the end of basin ranges from $0.15 \mathrm{~m} / \mathrm{s}$ to $0.22 \mathrm{~m} / \mathrm{s}$.

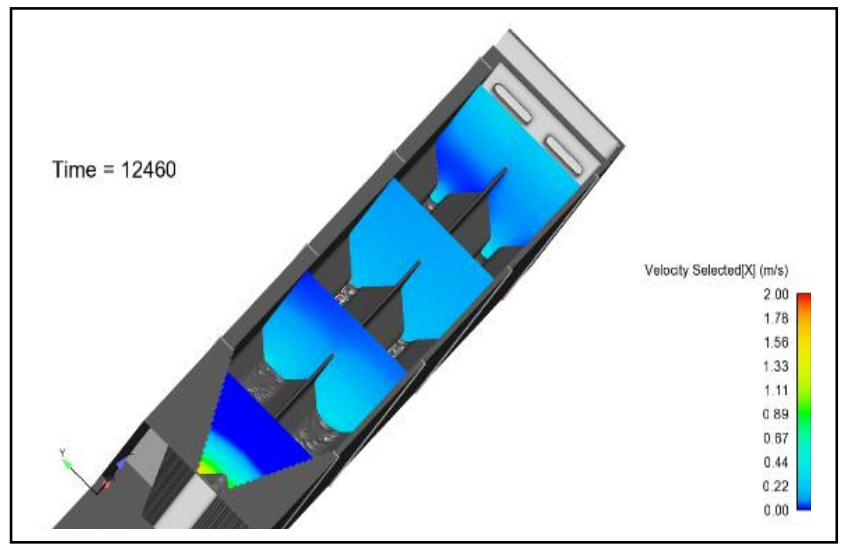

Figure 5: Distribution of horizontal velocity at different sections of the base case

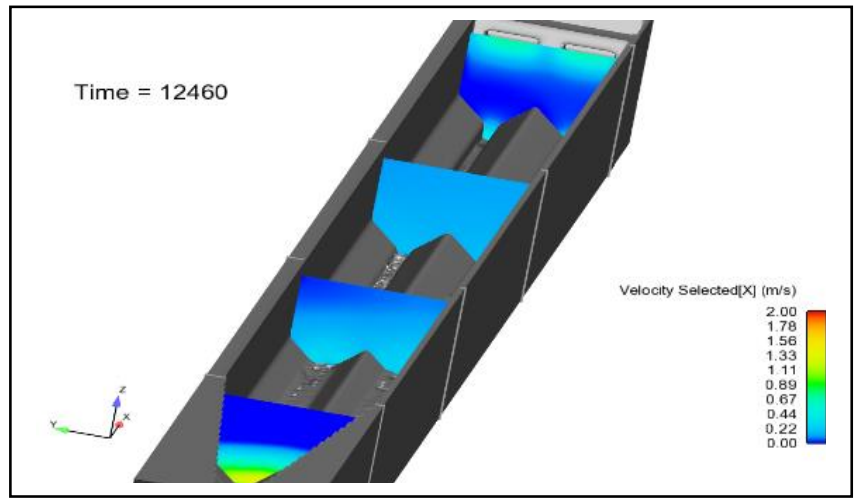

Figure 6: Distribution of horizontal velocity at different sections of the case I

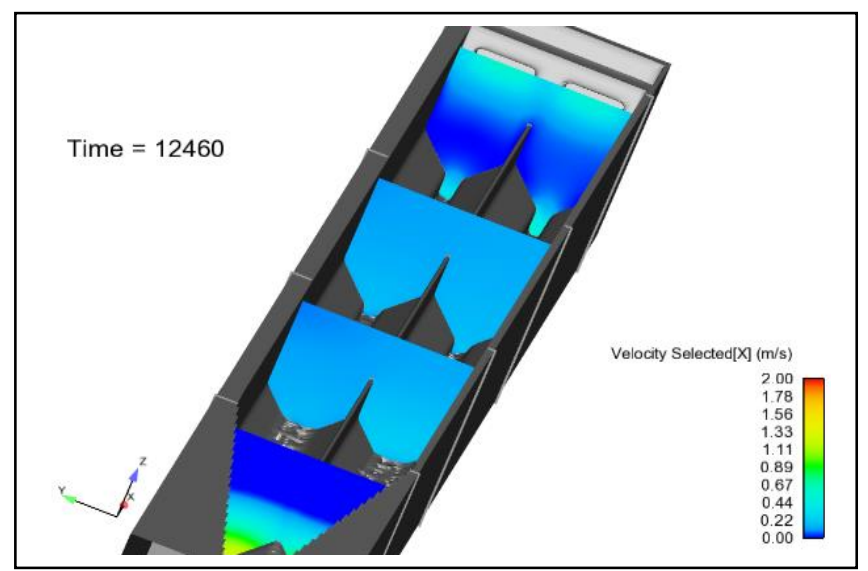

Figure 7: Distribution of horizontal velocity at different sections of the case II

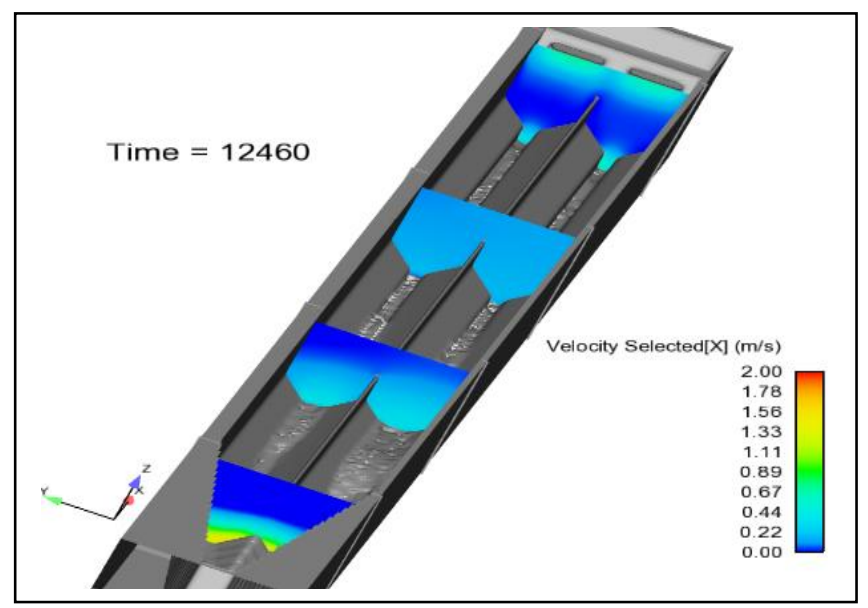

Figure 8: Distribution of horizontal velocity at different sections of the case III

Figure 9, Figure 10, Figure 11, and Figure 12 respectively represent the suspended sediment concentration at the same section at the end of simulation for the base case, modified case I, modified case II and modified case III respectively where sediment concentration distribution is seen similar. 


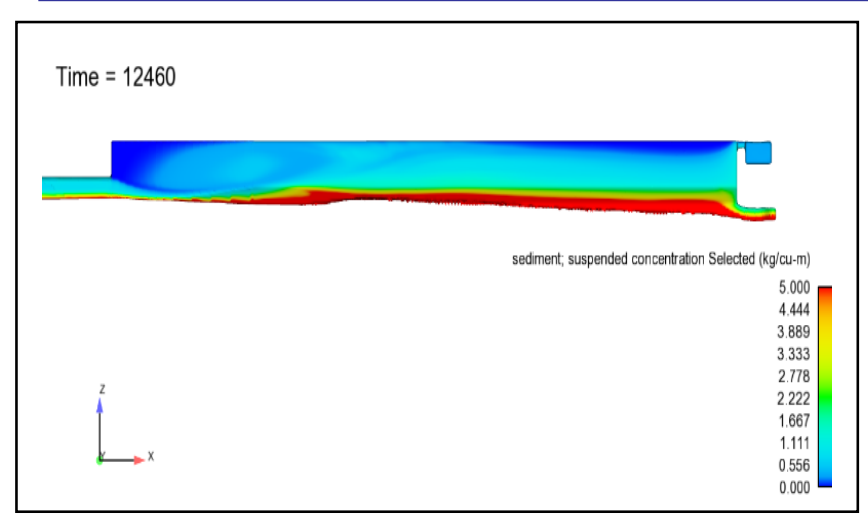

Figure 9:Sediment suspended concentration of the base case

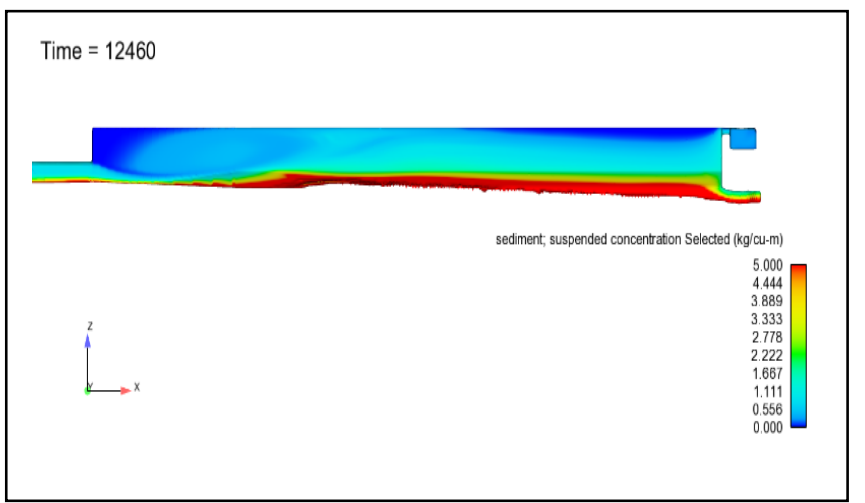

Figure 10: Sediment suspended concentration of the case I

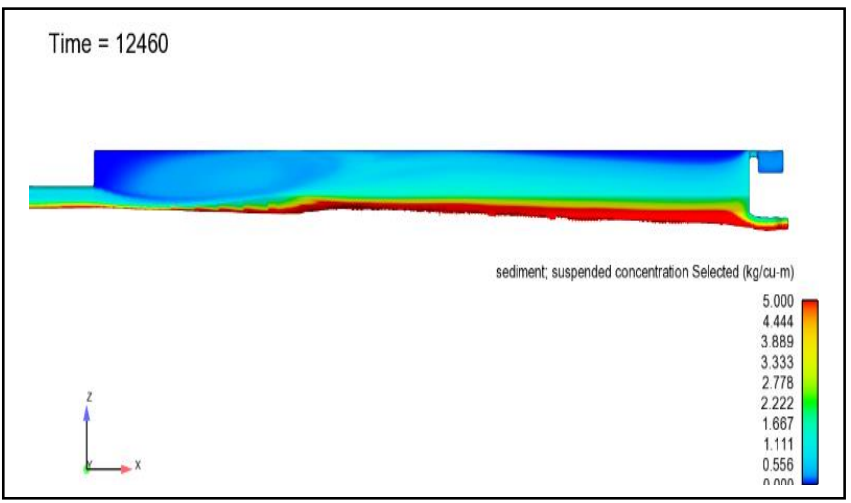

Figure 11: Sediment suspended concentration of the case II

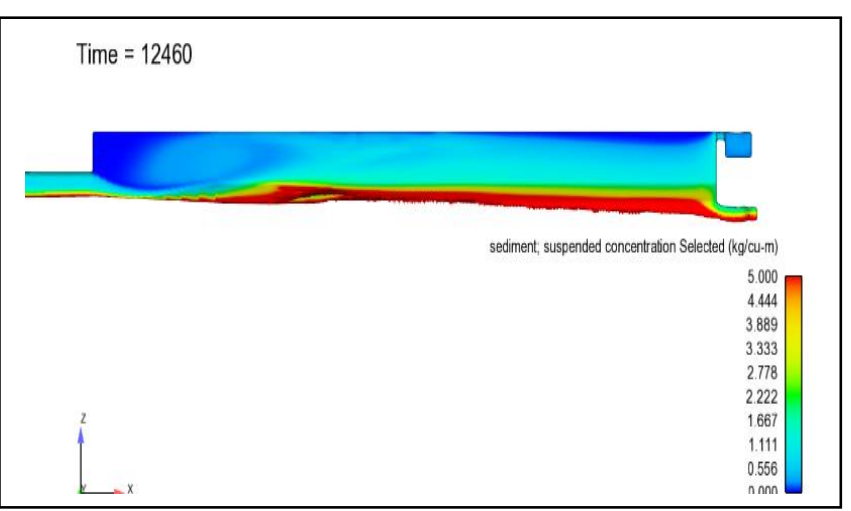

Figure 12: Sediment suspended concentration of the case III

Six probes are defined at three different sections as shown in Figure 13 to view the change in velocity. The plot between velocity and time at those probes are shown in Figure 14, Figure 15, Figure 16 and Figure 17 for the base case, modified case I, modified case II and modified case III respectively. In all the cases it is seen that velocity converges toward fixed value with time, which reflects the stability of simulation. In all the cases, except case II, the velocity at probe 1 and probe 2 is higher as this is just after the transition length whereas in case II, the velocity in all probes is of similar magnitude.

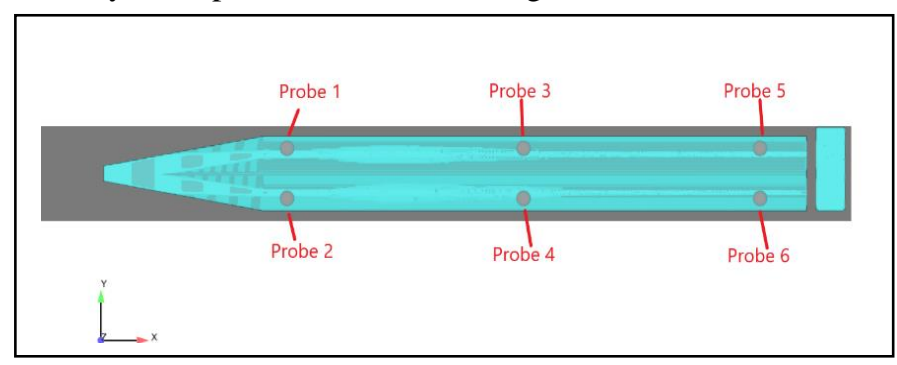

Figure 13: Probe defined to measure velocity

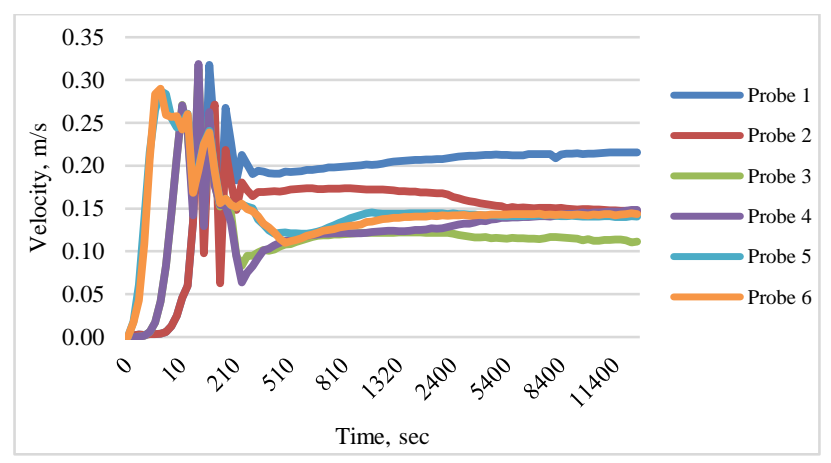

Figure 14: Velocity vs time graph at the defined probes of the base case

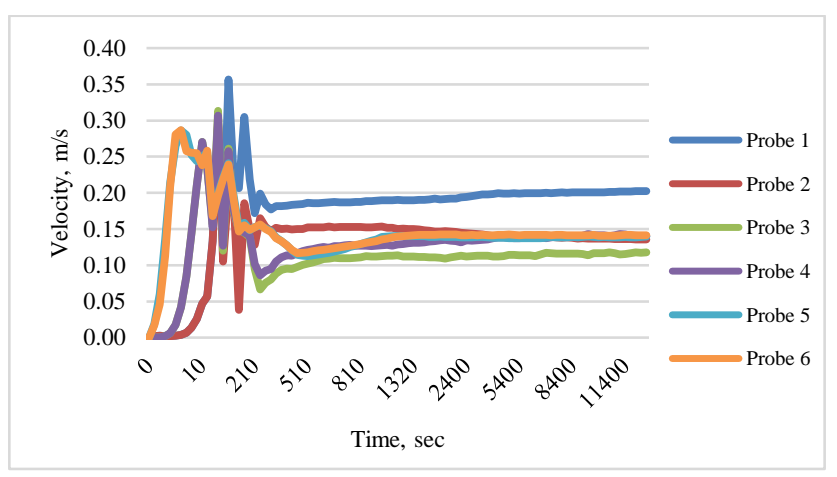

Figure 15: Velocity vs time graph at the defined probes of the case I

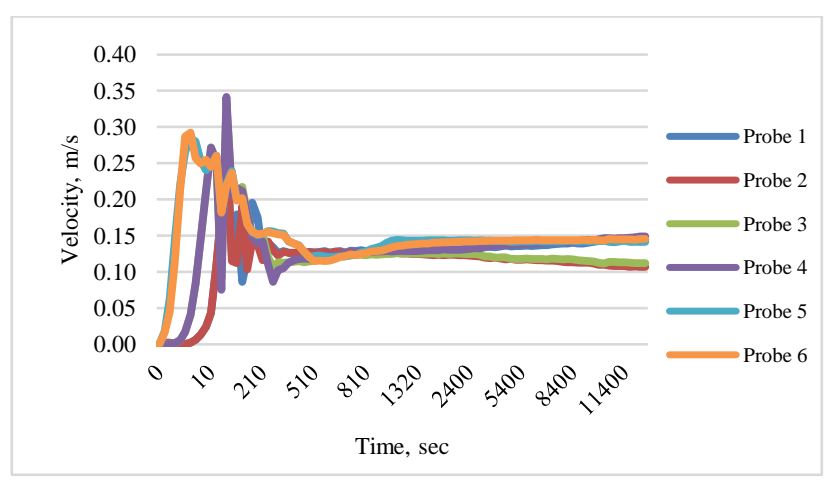

Figure 16: Velocity vs time graph at the defined probes of the case II 


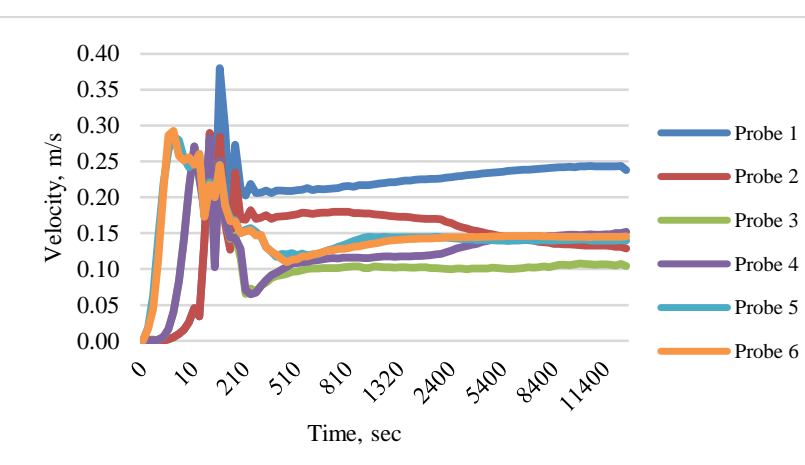

Figure 17: Velocity vs time graph at the defined probes of the case III

Figure 18 to Figure 21 represents the longitudinal sectional view of settling basin with sediment net change in height for the base case, modified case I, modified case II and modified case III respectively. The sections are viewed in the middle of each hopper. It is found most of the deposition has taken place just after the end of the transition. At the end of the simulation in the right hopper the maximum deposition of sediments was found to be $0.97 \mathrm{~m}, 1.06 \mathrm{~m}, 0.99 \mathrm{~m}$, and $1.32 \mathrm{~m}$ respectively for the base case, modified case I, modified case II and modified case III respectively. Similarly, in the left hopper the maximum deposition was $1.24 \mathrm{~m}, 1.19 \mathrm{~m}, 1.04 \mathrm{~m}$, and $1.15 \mathrm{~m}$ respectively for the base case, modified case I, modified case II and modified case III respectively.

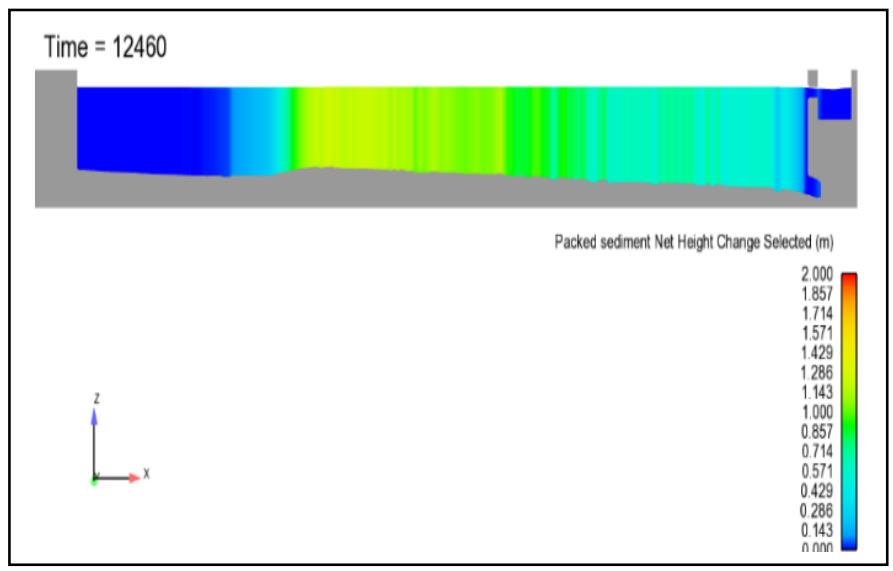

Figure 18: Sediment depth at the end of the simulation in the base case

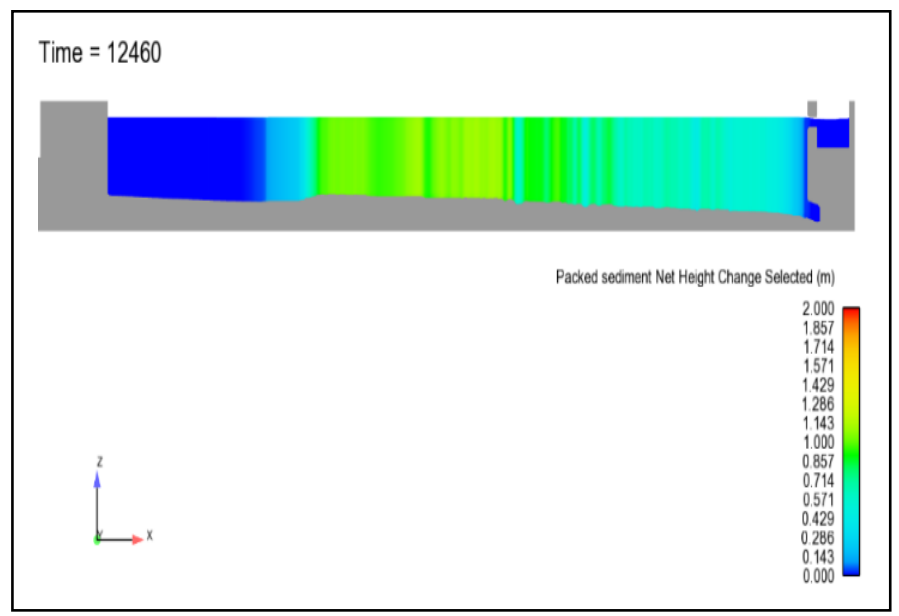

Figure 19: Sediment depth at the end of the simulation in the case I

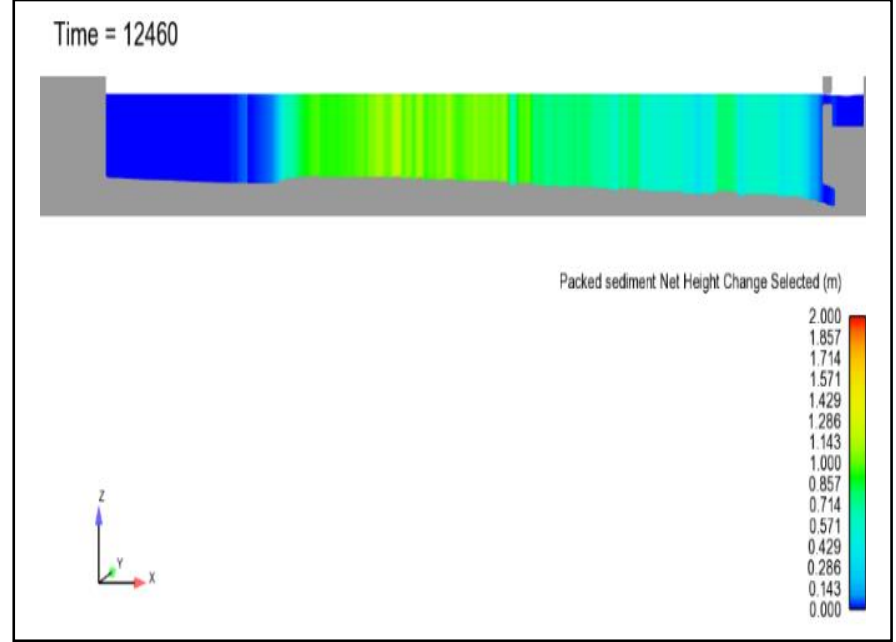

Figure 20: Sediment depth at the end of the simulation in the case II

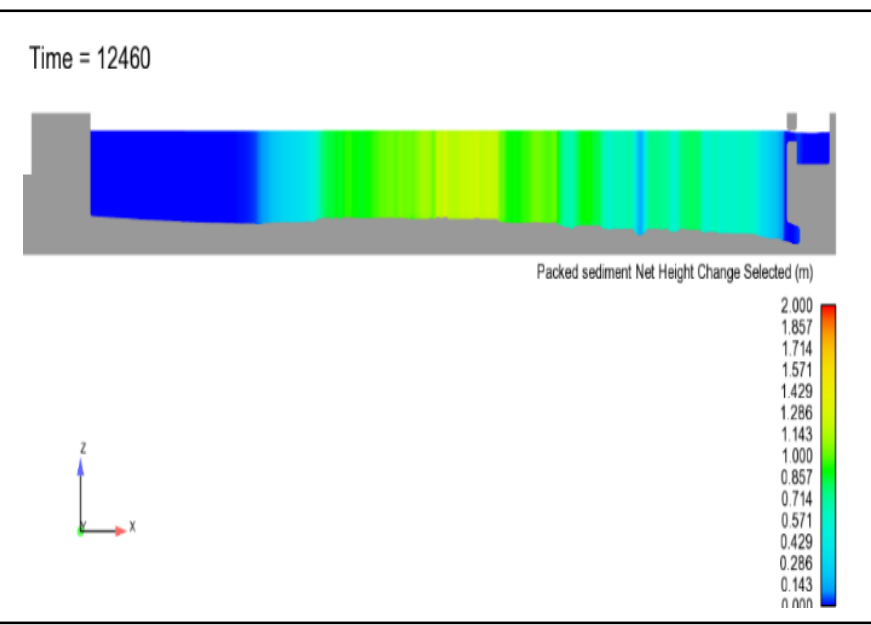

Figure 21: Sediment depth at the end of the simulation in the case III

It is supposed to settle sediment with a diameter of $+0.20 \mathrm{~mm}$ by the settling basin of BHP. The $0.20 \mathrm{~mm}$ sediment particles are expected to settle with a velocity magnitude of nearly 0.2 $\mathrm{m} / \mathrm{s}$. It is found that the horizontal velocity distribution in the basin is less than $0.2 \mathrm{~m} / \mathrm{s}$. Therefore, the settling basin is operative for sediment size $+0.20 \mathrm{~mm}$. The trap efficiency for the range of sediment $1.00-0.25 \mathrm{~mm}, 0.25-0.180 \mathrm{~mm}, 0.180-$ $0.075 \mathrm{~mm}$ and below $0.075 \mathrm{~mm}$ respectively are $100 \%, 100 \%$, $85.76 \%$ and $24.62 \%$ respectively. The overall trap efficiency of the settling basin obtained for about 3.5 hours $(12460 \mathrm{sec})$ is about $53.12 \%$ whereas for particle above $0.20 \mathrm{~mm}$ is $99 \%$. In the physical model, the trap efficiency for the range of sediment $1.00-0.25 \mathrm{~mm}, 0.25-0.180 \mathrm{~mm}, 0.180-0.075 \mathrm{~mm}$ and below $0.075 \mathrm{~mm}$ respectively are $100 \%, 82.67 \%, 45.32 \%$, and $23.88 \%$ respectively whereas overall trap efficiency is $34.34 \%$ and for $+0.20 \mathrm{~mm}$ is $87.66 \%$. The comparison of trap efficiency between numerical and physical modeling is shown in Figure 22. The trap efficiency comparison between the base case and modified cases that are obtained from numerical simulation is shown in Figure 23. It shows the overall trap efficiency of modified case II (i.e. transition angle $8^{\circ}$ ) is better than the other cases. 


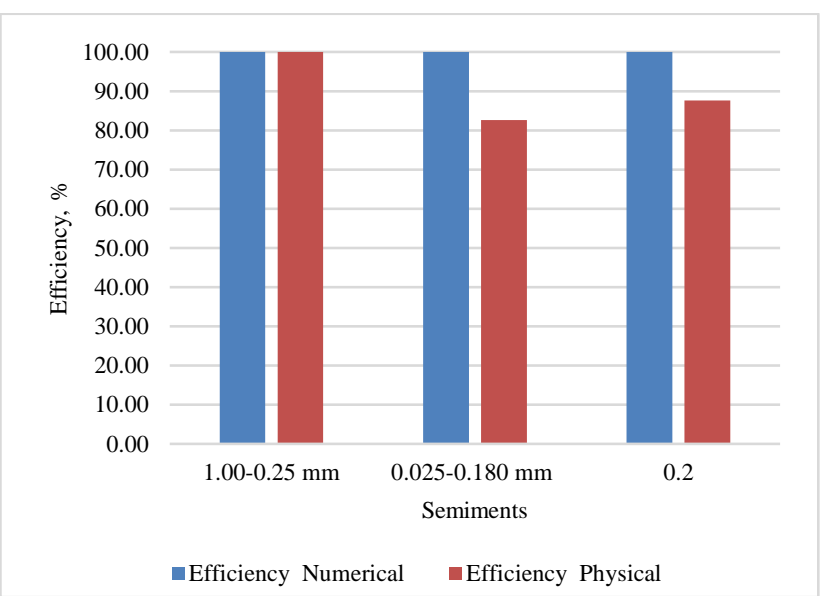

Figure 22: Efficiency, $\%$ at the end of the simulation for the base cases in physical and numerical modeling

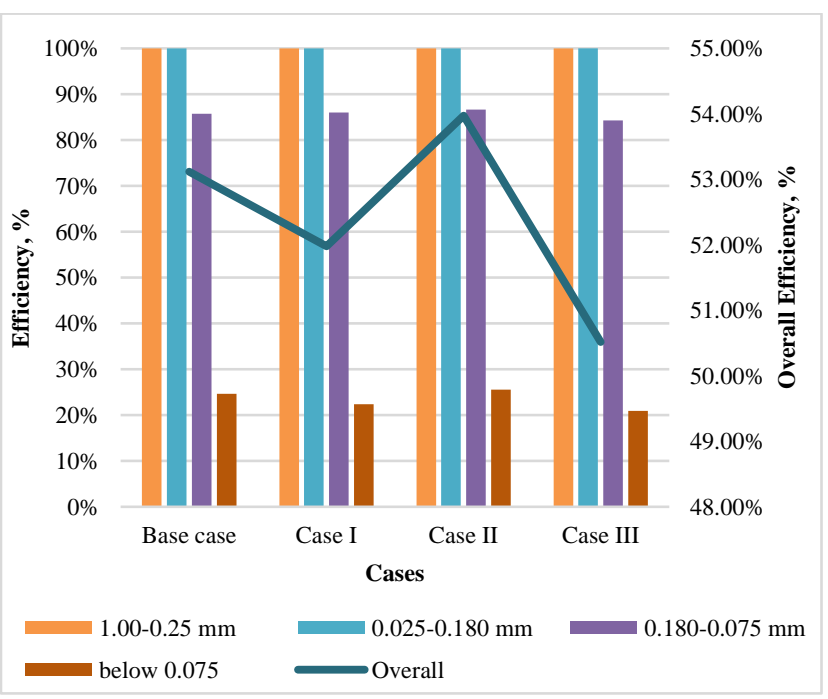

Figure 23: Efficiency, $\%$ at the end of the simulation for the different cases

\section{CONCLUSIONS}

In this study, the flow velocity, particle distribution, and concentration of the sediment particles at different time intervals are studied for BHP. These parameters obtained from numerical modeling is used to obtain the trap efficiency of the settling basin with time. The following conclusion has been drawn in this study:

1. The velocity obtained for all cases for the particles greater than $+0.20 \mathrm{~mm}$ is around $0.2 \mathrm{~m} / \mathrm{s}$, which seems good agreement with the value obtained from the empirical result.

2. The overall trap efficiency of the base case obtained from numerical modeling is $53.12 \%$ whereas physical modeling is $34.34 \%$. Similarly, for case I, case II, and case III, the result obtained was $51.98 \%, 53.97 \%$, and $50.52 \%$ respectively.

3. Among the cases, trap efficiency for case II seems a more efficient basin whose overall trap efficiency is $53.97 \%$.

4. In the different cases run, the case doesn't have a dividing wall and it has lower trapping efficiency compared to other cases although the deposition pattern with the base case is similar. Thus, the dividing wall plays a significant role in boosting the capacity of the settling basin.

5. It is recommended to conduct a couple of simulations with modification in the slope of the settling basin. The CFD calculation can deliver various useful information for obtaining trap efficiency and functioning of settling basin in hydropower projects.

\section{ACKNOWLEDGEMENT}

The authors are grateful to Department of Civil Engineering and Department of Mechanical Engineering at Pulchowk Campus, Institute of Engineering (IOE) for the support of work. We would like to acknowledge SMECUDAYA JV (A Joint Venture of SMEC International Pvt Ltd Australia and UDAYA Consultancy Pvt. Ltd Nepal) for providing necessary drawings along with report of the physical hydraulic model test of Budhi-Ganga Hydropower Project (BHP) conducted by Irrigation \& Power Research Institute (IPRI) Amritsar, Punjab, India. We would like to express our cordial thankfulness to Flow Science, Inc. for developing and providing FLOW-3D program.

\section{REFERENCES}

[1] B. Carson, "Erosion and Sedimentation Process in the Nepalese Himalya," ICIMOD occasional paper No. 1, Kathmandu, Nepal, 1985.

[2] M. B. Bishwakarma, "Settling Basin Design Criteria and Trap Efficiency Computation Methods," Department of Hydraulics and Encironmental Engineering, NTNU, Trondheim, Norway, 1997.

[3] H. Novik, A. Dudhraj, P. N. R. Olesen, D. M. B. Bishwakarma and P. L. Lia, "Numerical Modeling of Non-uniform Flow in Settling Basin," Hydro Nepal, 2014.

[4] S. E. Lewis, Z. T. Bainbridge, P. M. Kuhnert, B. S. Sherman, B. Henderson, C. Dougall, M. Cooper and J. E. Brodie, "Calculating sediment trapping efficiencies for reservoirs in tropical settings: A case study from the Burgekin Falls Dam, NE Australia," WATER RESOURCES RESEARCH, vol. 49, p. 1017-1029, 2013.

[5] S. L. Barbour and J. Krahn, "Numerical Modeling- Prediction or Process?," GeoSpec, pp. 44-52, 2004.

[6] Torres, C. Borman, D. Sleigh and A. e. al., "Three-Dimensional Numerical modeling of full-scale hydraulic structures," International Association for Hydro-Environment Engineering Research (IAHR), pp. 1335-1343, 2017.

[7] S. Heimsund, E. W. M. Hansen and W. Nemec, "Computational 3-D fluid-dynamics model for sediment transport, erosion and deposition by turbidity currents," IAS 16th International Sedimentological Congress, pp. 151-152, 2002.

[8] FLOW-3D, "FLOW-3D Version 11.2 Users Manual," Flow Science, Inc. https://www.flow3d.com, Santa Fe, NM, USA, 2017.

[9] H. Dhemi, K. N. Dantje, A. Mohammad Bagus, M. Hernawan and A. Fitra, "3D Numerical Modeling of Flow in Sedimentation Basin," MATEC Web of Conferences, 2018.

[10] B. V. Shrestha, "3D Numeriacl Investigation on Settling Basin Layout: A case study on Mai Khola Hydropower Project, Nepal," NTNU, Trondheim, Norway, 2012.

[11] D. K. Lysne, B. Glover, H. Stole and E. Tesaker, HYDROPOWER DEVELOPMENT HYDRAULIC DESIGN, vol. 8, Trondheim, Norway: Norwegian University of Science and Technology, 2003.

[12] I. \&. P. R. I. team, "Desander Hydraulic Model Test Report," IRRIGATION \& POWER RESEARCH INSTITUTE, Amritsar, Punjab, India, 2019. 